\title{
Development of an immobilization device based on the criteria from different users
}

\author{
Mateus Zanatta, Grasiele Rama \\ Universidade de Caxias do Sul \\ e-mails: mzanatt2@ucs.br; grama@ucs.br
}

\begin{abstract}
This study is set in the context of the care of trauma patients with suspected spine trauma and the use of immobilization devices to prevent secondary trauma. The aim of the current study is develop a concept of vest immobilization device that meets the needs of the users - in this case defined as patients, care teams, and cleaning/ decontamination professionals. To this end, we developed a list of requirements and restrictions defined by a usability test with PreHospital Trauma Life Support (PHTLS) and Advanced Trauma Life Support (ATLS) teams. Then a list of solutions, realized through benchmarking, shows the best practices from industry. Finally, a multi-criteria decision-making analysis defines the importance of requirements and shows the best solutions to new immobilization device development. Based on the results obtained, a concept of immobilization device created for patients with suspected spinal injury presents an alternative that meets the user's needs.
\end{abstract}

Keywords: multiple-criteria decision-making, usability, healthcare.

\section{Introduction}

Spine traumas are normally associated with traffic accidents, sports injuries and falls (BROWN; BRUNN; GARCIA, 2001; BURNEY et al., 1993; CLAYTON et al., 2012; OLIVER et al., 2012). In these cases, improper patient handling can cause an aggravation of the injury and lead to irreversible damage to the spinal cord. In order to prevent this complication, emergency medical services always consider Spinal Cord Trauma (SCT) when the victim was exposed to intense forces, as a result of sharp movements in the region of the spine due to abrupt deceleration, as in the cases described (NATIONAL..., 2007).

Careful movement and the use of appropriate extrication techniques are crucial in all patients suspected to have SCT (BERNHARD et al., 2005; CASTELLANO, 2007) while avoiding the aggravation of injuries caused by accidents (CASTELLANO, 2007; NATIONAL..., 2007). Especially considering that the lack of immobilization of the spine in patients whose injuries are not diagnosed at initial evaluation is considered the main cause of secondary injury (CROSBY, 2006). To prevent improper patient handling, Richard L. Kendrick created a device to be used in traffic accidents (KENDRICK, 1980). His concept, the Kendrick Extrication Device (KED), was an evolution of spine immobilization devices such as stretchers (FLETCHER, 1964; LUCCI; REED, 1943; SPRINGER, 1949), short boards (DIXON; PROCTOR, 1973; PHILLIPS, 1969; SHERMAN, 1979), vests (WEIDEMANN JUNIOR, 1956), and splints (FRANCES, 1960).
Systems of immobilization such as the KED in combination with a Rigid Cervical Collar (RCC) are useful to provide almost complete immobilization of the head and back (BERNHARD et al., 2005; CASTELLANO, 2007). These devices together are often used to immobilize patients with suspected SCT during extrication after a motor vehicle crash (BERNHARD et al., 2005; WINTERBERGER et al., 2008), but they can also be used to advantage in difficult terrain, especially when there is lack of space such as in a narrow crevasse (WINTERBERGER et al., 2008). However, the use of these devices is performed only in hemodynamically stable patients (BERNHARD et al., 2005; NATIONAL..., 2007) because the theoretical risk of an unstable spine is outweighed by the harm caused by rapid cardiovascular decompensation (CALLAND, 2005).

Based on the benefits offered by these immobilization devices for trauma patients, this study proposes a new concept for a vest immobilization device, based on the needs of the users. The users, in this context include PreHospital Trauma Life Support (PHTLS) and Advanced Trauma Life Support (ATLS) teams, who use the devices for performing the work of immobilization, transport and care. In addition, the professionals who perform steps after life support, like cleaning and decontamination of the equipment are included.

Considered restrictions about KED use by the PHTLS and ATLS teams includes the treatment to SCT and associated traumas, presented in (NATIONAL..., 2007) as 
usually facial, thoracic and traumatic brain injury. Thus, the device should allow the access for anatomical regions involved. For ATLS team sometimes is needed the use of medical imaging and emergency surgery, depending on the condition of the patient. For cleaning/decontamination team, how easy and quickly they can finish their work determines the product efficiency. Although improved functionality for workers involved in care is justifiable by easy and quickly care, is necessary to consider that these features cannot endanger patient safety, as the product main focus the total immobilization of the head and back. This safety condition relies on the ability of the device in supporting the body in a neutral position and to the ability in coupling to patient body and other devices used together as long board and RCC.

\section{Method}

Based on the medical literature, regarding to the care of victims with suspected SCT, the authors developed a threestep method including data gathering (creation of the list of workers needs and use restrictions), prioritization (definition of the most important procedures and the best alternatives), and product development (concept that meets the needs face of use restrictions).

First, aiming to gather relevant information about the needs of the users, and the existing market solution, researchers performed open interviews with some members of the PHTLS and ATLS teams. These professionals showed their needs and restrictions whereas using immobilization devices and other equipment used together to perform life support. In addition, usability tests, realized during simulated attendances, allow team members to perform the tasks, and thus explain their difficulties. In the simulation, PHTLS team performed the extrication of the patient seated inside a car using KED and RCC, such as in a typically traffic accident. After, the team concluded the immobilization accomplishing KED to a backboard, followed by other procedures of life support, such as airway management, intravenous access, resuscitation and automated external defibrillation to cite a few. For the ATLS team, only interviews are conducted, aiming to researchers understand the needs about emergency care, such as medical imaging (to identify SCT, internal bleeding and other traumas) and emergency surgery (sometimes needed before SCT intervention in the presence of severe internal bleeding). To finish this step, a survey from existing products for full or partial immobilization, returned important characteristics, which can be used in the new immobilization device.

Second, and using the information retrieved, was conducted the prioritization of the needs and solutions through multi-criteria decision-making matrices. An Analytical Hierarchical Process (AHP) (SAATY, 1977) prioritized the functions needed for the immobilization device. An adapted PUGH decision matrix (PUGH, 1981) was used to prioritize key solutions presented in existing products to select the best choice for each feature to perform the functions needed. However, different to original PUGH scale, that use 3 degrees of classification $(-1,0,+1)$ the researchers used 7 degrees, between 3 positive and negative, where 0 represent equivalence between alternatives, the higher values represent the best alternatives and the negative values tends to incompatibility of the alternative. The bigger scale as so defined to penalize incompatible solutions and prioritize higher differences between the best alternatives. The entire matrices was completed with the assignments of PHTLS and ATLS teams, including some workers involved in cleaning/decontamination processes, and the imputed data is defined by consensus. The integration of the different professionals involved in the process had the objective of avoid biased development.

Finally, we show a concept of immobilization device, based on the best of possible solutions for each feature, presented in data gathering, prioritized by multi-criteria analysis, and thus attending the user's requirements and restrictions.

\section{Results and discussion}

Based on ergonomic approach (GUÉRIN et al., 2001), it is known that is needed to understand the work before transform it. Thus, PHTLS and ATLS teams showed the functions needed to perform the work through open interviews. The functions cited includes many times the patient immobilization, but to do this, PHTLS team can be fast and safe (which include good body coupling and easy handling), and can do other procedures of life support until arrives to the hospital. Standing with the patient in the hospital, ATLS team can do other procedures, which include the diagnostic of SCT and others that can lead the patient to death. For this, the equipment of medical imaging is required, and depending on the severity of the injuries, the patient can be submitted to other emergency surgeries, before the diagnostic of SCT. In these cases, the patient remain fixed, since the immobilization devices do not affect the surgery. Whereas the work of PHTLS and ATLS teams are made to preserve the physical integrity of the patient, can be considered that the needs of these professional are the needs of the patient. In addition to these functions, it is necessary to clean the device, so it can be quickly submitted to the use, since it represents a high cost for the emergency service. Thus, is pointed by the professionals that cleaning should be easy, fast, and need to consume fewer resources. All the functions needed are summarized as safe and quickly immobilization with easy handling and good body coupling, doing this without restricting life support procedures and medical imaging, and finally be easy cleaning (Table 1).

To enhance knowledge about restrictions a usability test was conducted and thus, some difficult tasks were identified, 
such as lack of space inner the car (Figures 1, 2 and 3), difficulties to positioning the device in the patient's back (Figure 1), the drop of straps used to secure the patient's head (Figure 2) and handling instability (Figure 3). The difficulties to positioning the device is because the tabs of the device are unstable and the drop of straps because the Velcro is stuck directly, without any mechanical friction mechanism. Instability during handling is created by the straps used to grip the hands to the device, causing insecurity by the PHTLS team.

Despite this study try to create a new concept to immobilization of patients with suspected SCT, exist some devices designed for this purpose (Table 2). Based on the characteristics of these devices, the results of a decision matrix (Table 3) determine for every part of the device, what is the best choice to reach the function needed. For the relative importance of the functions, the professional involved in research, selected to be the best alternatives, the procedures that directly affects the patient's life, such as safety immobilization and access to emergency procedures. In this context, a fast immobilization represents a shorter time to arrive to emergency care center, where the patient has more resources for life support. Is evident here that the responses of the professionals involved in these operations follow strictly the standard procedures, as pointed out in the literature, possibly due to constant training in this type of work. Is evident that in case of an emergency or urgent care that easy cleaning/decontamination of the device has the less importance. However, looking at the concept created, it is perceived was possible to create a product that meets the service requirements quickly and safety, and cleanliness requirements too (Figures 4, 5 and 6). The main body, made with a sheet of polyethylene, formed into an organic form, allowing the PHTLS team to the quickly immobilization

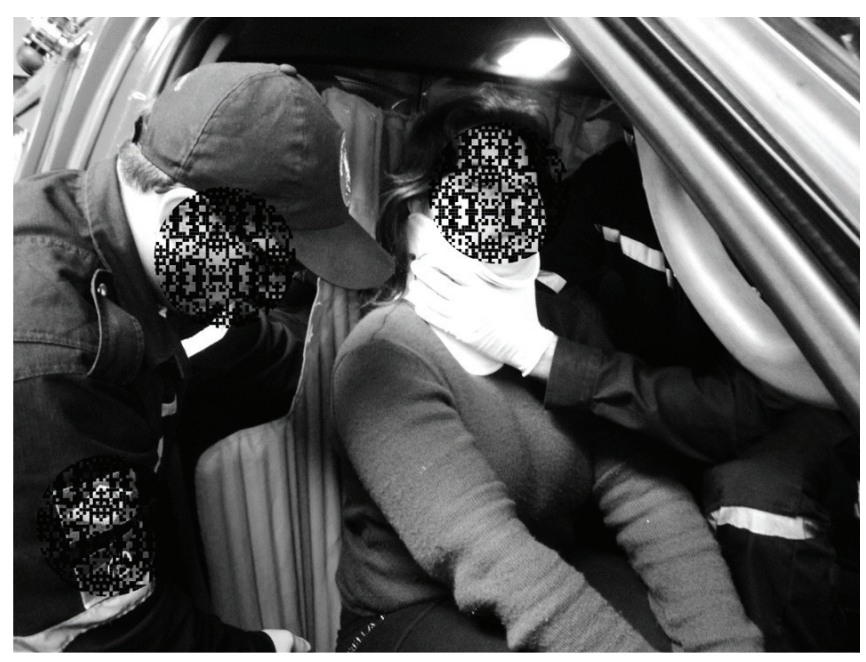

Figure 1. Positioning KED in the back.

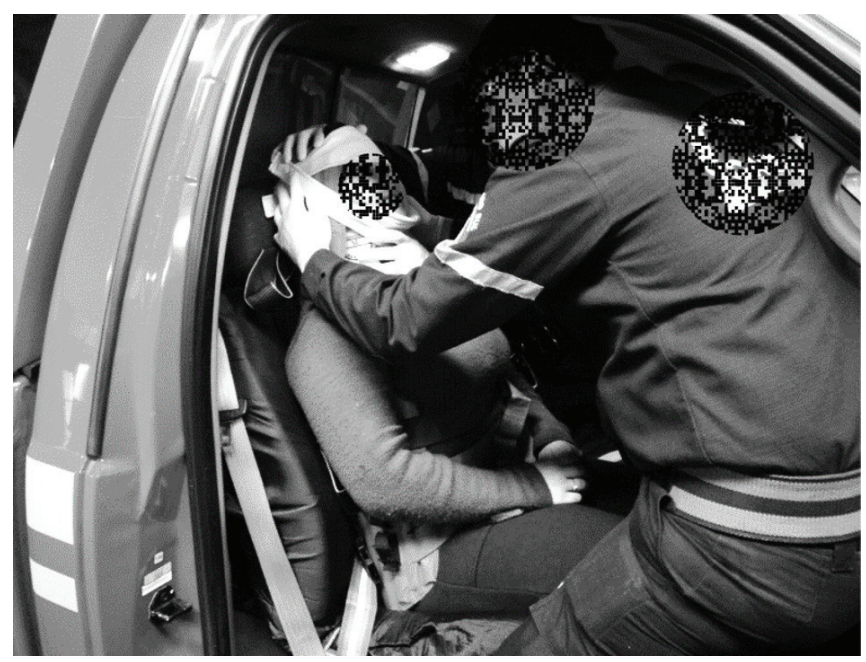

Figure 2. Fixing the risers of the head.

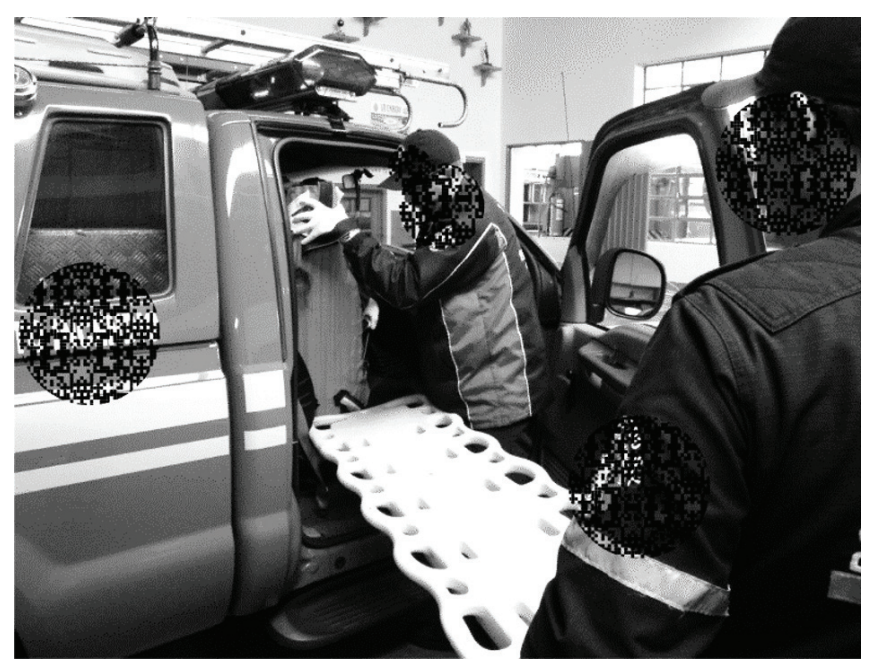

Figure 3. Removing from the car with backboard assist.

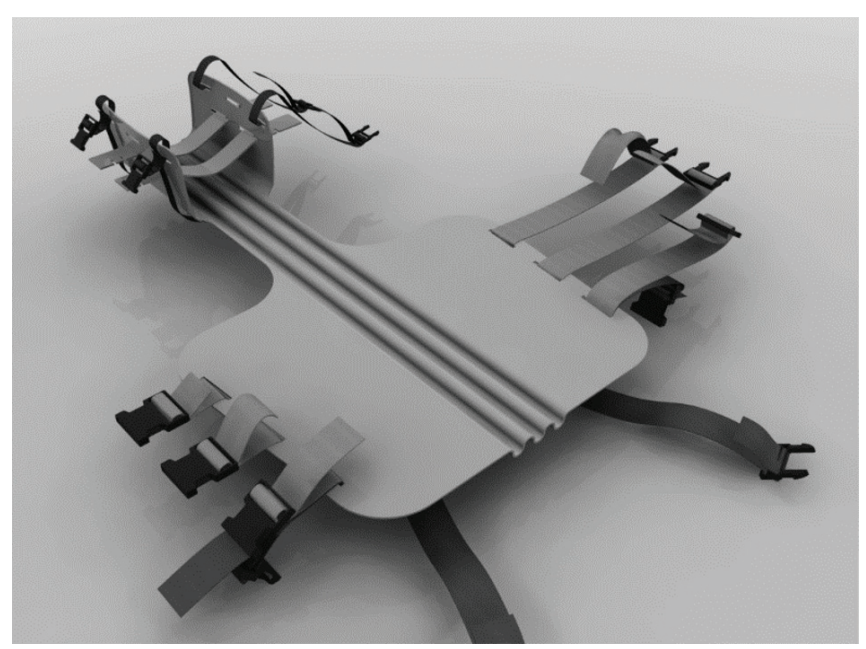

Figure 4. Concept of immobilization device open. 


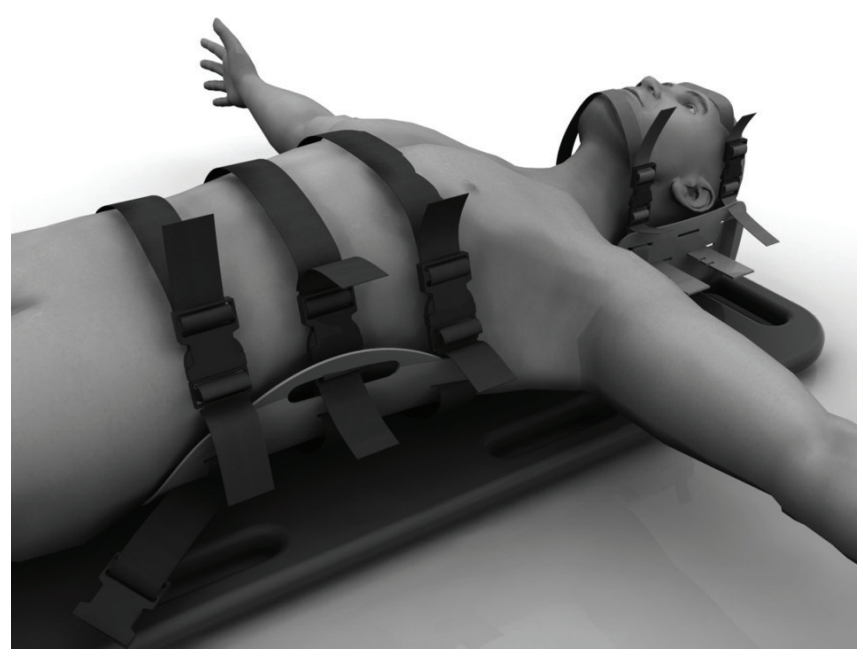

Figure 5. Concept of immobilization device coupled to the patient and to the backboard.

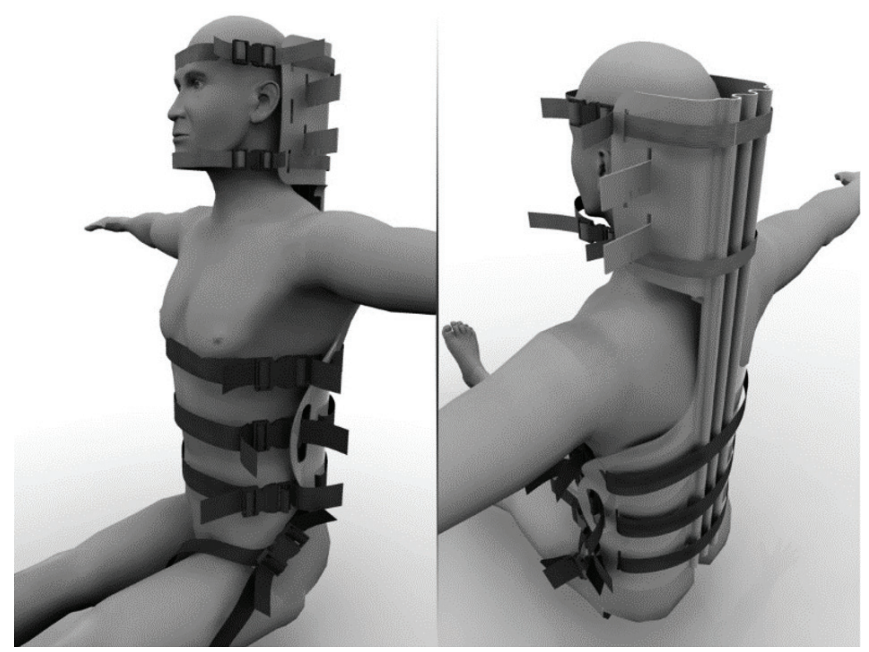

Figure 6. Concept of immobilization device coupled to the patient in sited position.

of the patient reducing instability. It is possible because in parallel to the column direction it is rigid while in perpendicular direction it is flexible. In addition, the flat/ organic form allow to cleaning workers complete their work in less time complete their work in less time since there are no grooves for accumulation of dirt. As for the ATLS team, the materials used have no restrictions to the medical imaging equipment, allowing complete procedures with immobilized patient. In addition, the closure mechanisms, not changed to the main body do not represent problems if the device needs to be removed, because they are so simple to open as closing.

In conclusion, the proposed method allows the participation of professionals in decision-making for product development. Moreover, it has fast result that meets the general needs without compromising safety requirements. Although this study only addressed a small group of users for a simple device with few parts, it may be possible to extend these boundaries to a greater number of professionals involved and for products with greater complexity.

\section{References}

BERNHARD, M. et al. Spinal cord injury (SCI): prehospital management. Resuscitation, v. 66, n. 2, p. 127-139, 2005. PMid:15950358. http://dx.doi.org/10.1016/j. resuscitation.2005.03.005

BROWN, R. L.; BRUNN, M. A.; GARCIA, V. F. Cervical spine injuries in children: a review of 103 patients treated consecutively at a level 1 pediatric trauma center. Journal of Pediatric Surgery, v. 36, n. 8, p. 1107-1114, 2001. PMid:11479837. http://dx.doi.org/10.1053/jpsu.2001.25665

BURNEY, R. E. et al. Incidence, characteristics, and outcome of spinal cord injury at trauma centers in north america. Archives of Surgery, v. 128, n. 5, p. 596599, 1993. PMid:8489395. http://dx.doi.org/10.1001/ archsurg.1993.01420170132021

CALLAND, V. Extrication of the seriously injured road crash victim. Emergency Medicine Journal, v. 22, n. 11, p. 817821, 2005. PMid:16244349 PMCid:PMC1726607. http:// dx.doi.org/10.1136/emj.2004.022616

CASTELLANO, J. M. Prehospital management of spinal cord injuries. Emergencias, v. 19, p. 25-31, 2007.

CLAYTON, J. L. et al. Risk factors for cervical spine injury. Injury, v. 43, n. 4, p. 431-435, 2012. PMid:21726860. http:// dx.doi.org/10.1016/j.injury.2011.06.022

CROSBY, E. T. Airway management in adults after cervical spine trauma. Anesthesiology, v. 104, n. 6, p. 1293-1318, 2006. PMid:16732102. http://dx.doi.org/10.1097/00000542200606000-00026

DIXON, A. E.; PROCTOR, M. Splints. UK Patent 1323422A, 18 july 1973.

FLETCHER, D. D. Invalid stretcher. US 3158875 A, 1 dez. 1964.

FRANCES, D. Bandage with removable splints. US 2957475 A, 25 oct. 1960.

GUÉRIN, F. et al. Comprendre le travail pour le transformer: la pratique de l'ergonomie. Lyon: ANACT, 2001.

KENDRICK, R. L. Spinal restraint device. EP 0013061 A1, 9 july 1980.

LUCCI, J. P.; REED, F. M. Safety carrier. US 2309464 A, 26 jan. 1943 
NATIONAL ASSOCIATION OF EMERGENCY MEDICAL TECHNICIANS - NAEMT. Atendimento pré-hospitalar ao traumatizado: PHTLS. Rio de Janeiro: Elsevier Brasil, 2007.

OLIVER, M. et al. The changing epidemiology of spinal trauma: a 13-year review from a Level I trauma centre. Injury, v. 43, n. 8, p. 1296-1300, 2012. PMid:22648015. http://dx.doi.org/10.1016/j.injury.2012.04.021

PHILLIPS, W. D. Fracture board. US 3469268 A, 30 set. 1969.

PUGH, S. Concept selection: a method that works. In: INTERNATIONAL CONFERENCE ON ENGINEERING DESIGN, 1981. Proceedings... Rome: Technique Nuove, 1981.

SAATY, T. L. A scaling method for priorities in hierarchical structures. Journal of Mathematical Psychology, v. 15, n. 3, p. 234-281, 1977. http://dx.doi.org/10.1016/00222496(77)90033-5

SHERMAN, S. W. Universal short spine board system. US 4143654 A, 13 mar. 1979.

SPRINGER, K. F. Litter. US 2489828 A, 29 nov. 1949.

WEIDEMANN JUNIOR, W. H. Immobilizing splint. US 2753864 A, 10 jul. 1956.

WINTERBERGER, E. et al. The use of extrication devices in crevasse accidents: official statement of the International Commission for Mountain Emergency Medicine and the Terrestrial Rescue Commission of the International Commission for Alpine Rescue intended for physicians, paramedics, and mountain rescuers. Wilderness \& Environmental Medicine, v. 19, n. 2, p. 108-110, 2008. PMid:18513106. http://dx.doi.org/10.1580/07-WEMECO-1012.1 


\section{Appendix}

Table 1. AHP for functions needed to suspected SCT patients.

\begin{tabular}{|c|c|c|c|c|c|c|c|c|c|c|c|c|c|c|c|}
\hline 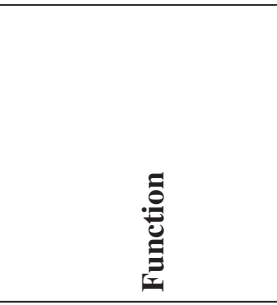 & 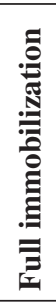 & 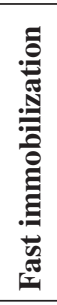 & 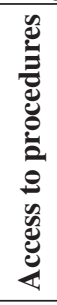 & 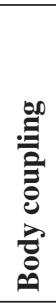 & 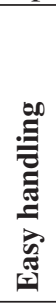 & 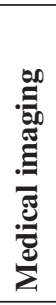 & 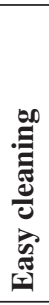 & \multicolumn{7}{|c|}{ 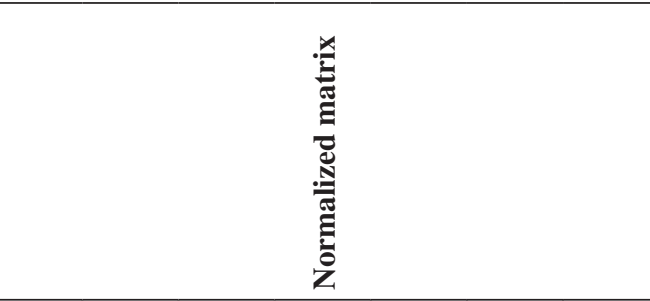 } & 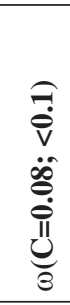 \\
\hline Full immobilization & 1 & 3 & 1 & 1 & 3 & 3 & 9 & 0.24 & 0.40 & 0.15 & 0.21 & 0.25 & 0.19 & 0.21 & 0.24 \\
\hline Fast immobilization & $1 / 3$ & 1 & 1 & 1 & 1 & 3 & 7 & 0.08 & 0.13 & 0.15 & 0.21 & 0.08 & 0.19 & 0.16 & 0.14 \\
\hline Access to procedures & 1 & 1 & 1 & $1 / 3$ & 5 & 5 & 9 & 0.24 & 0.13 & 0.15 & 0.07 & 0.41 & 0.31 & 0.21 & 0.22 \\
\hline Body coupling & 1 & 1 & 3 & 1 & 1 & 3 & 7 & 0.24 & 0.13 & 0.46 & 0.21 & 0.08 & 0.19 & 0.16 & 0.21 \\
\hline Easy handling & $1 / 3$ & 1 & $1 / 5$ & 1 & 1 & 1 & 5 & 0.08 & 0.13 & 0.03 & 0.21 & 0.08 & 0.06 & 0.12 & 0.10 \\
\hline Medical imaging & $1 / 3$ & $1 / 3$ & $1 / 5$ & $1 / 3$ & 1 & 1 & 5 & 0.08 & 0.04 & 0.03 & 0.07 & 0.08 & 0.06 & 0.12 & 0.07 \\
\hline Easy cleaning & $1 / 9$ & $1 / 7$ & $1 / 9$ & $1 / 7$ & $1 / 5$ & $1 / 5$ & 1 & 0.03 & 0.02 & 0.02 & 0.03 & 0.02 & 0.01 & 0.02 & 0.02 \\
\hline
\end{tabular}

Scale: 1) same importance; 3) weakly important; 5) more important; 7) strongly important; 9) extremely important.

Table 2. Characteristics of devices used to rescue patients with suspected SCT.

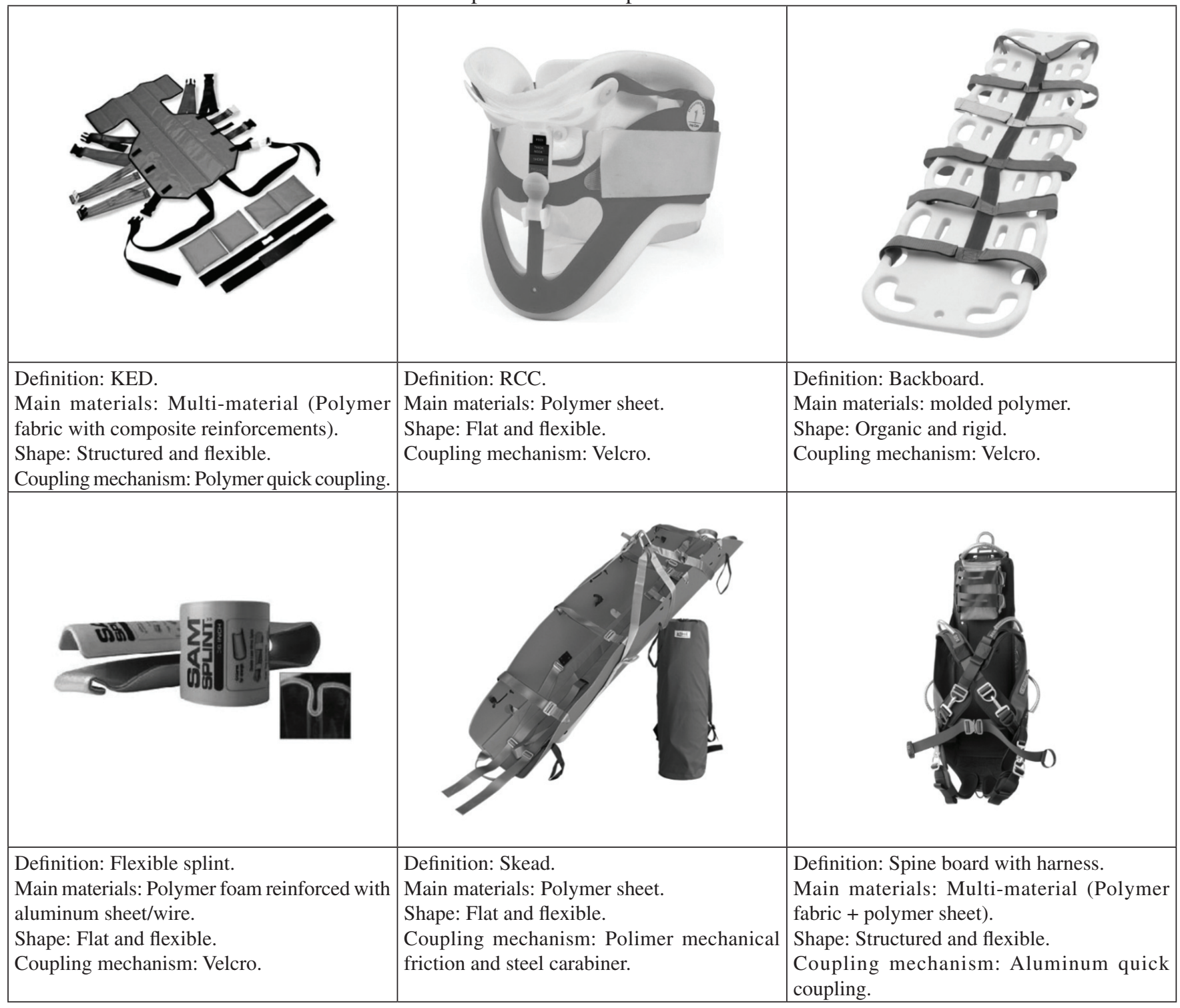


Table 3. Comparison between desired functions and alternatives for material, shape and coupling mechanisms.

\begin{tabular}{|c|c|c|c|c|c|c|c|c|c|c|c|c|c|c|c|}
\hline \multirow[b]{2}{*}{ 莺 } & \multirow[b]{2}{*}{ 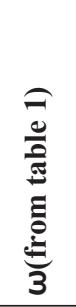 } & \multicolumn{3}{|c|}{ Material } & \multicolumn{3}{|c|}{ Shape } & \multicolumn{2}{|c|}{ Flexibility } & \multicolumn{6}{|c|}{ Coupling mechanism } \\
\hline & & 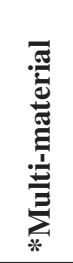 & 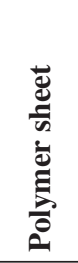 & 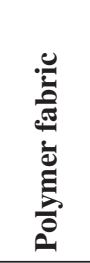 & 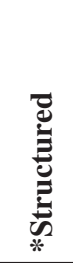 & 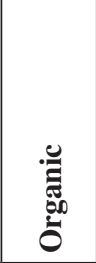 & $\frac{\vec{I}}{I}$ & $\begin{array}{l}\frac{0}{0} \\
\frac{0}{0} \\
\frac{0}{0} \\
*\end{array}$ & 鹿 & 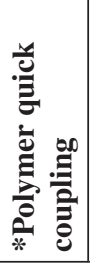 & 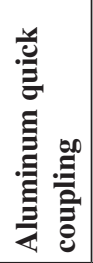 & $\frac{\otimes}{\stackrel{0}{0}}$ & 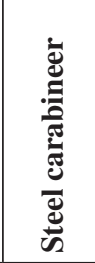 & 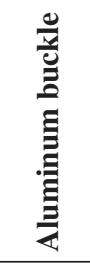 & 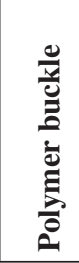 \\
\hline Full immobilization & 0.24 & 0 & 0 & -2 & 0 & -1 & -1 & 0 & 0 & 0 & 0 & -1 & -1 & 0 & 0 \\
\hline Fast immobilization & 0.14 & 0 & 1 & -2 & 0 & 1 & 1 & 0 & 1 & 0 & 0 & 1 & 0 & -2 & -2 \\
\hline Access to procedures & 0.22 & 0 & 0 & 0 & 0 & 0 & 0 & 0 & 0 & 0 & 0 & 0 & 0 & -1 & -1 \\
\hline Body coupling & 0.21 & 0 & -1 & 1 & 0 & -1 & 0 & 0 & -2 & 0 & 0 & 0 & 0 & 0 & 0 \\
\hline Easy handling & 0.10 & 0 & 1 & 0 & 0 & 1 & 1 & 0 & 1 & 0 & 0 & 0 & 0 & 0 & 0 \\
\hline Medical imaging & 0.07 & 0 & 0 & 0 & 0 & 0 & 0 & 0 & 0 & 0 & -3 & 0 & -3 & -3 & 0 \\
\hline Easy cleaning & 0.02 & 0 & 3 & 1 & 0 & 2 & 3 & 0 & 0 & 0 & 0 & -1 & 0 & 0 & 0 \\
\hline Heights & & 0.00 & 0.10 & -0.53 & 0.00 & -0.16 & 0.07 & 0.00 & -0.18 & 0.00 & -0.21 & -0.11 & -0.44 & -0.71 & -0.51 \\
\hline
\end{tabular}

*Baseline for comparison (KED). Source: Adapted from Decision-Matrix Method (PUGH, 1981). Scale (defined by the authors): 0) equal; 1) little better;

2) better; 3) far better; -1) little worse; -2) worse; -3) incompatible. 